\title{
SIMULASI PENJADWALAN POSISI PANEL SURYA DENGAN MENGGUNAKAN PENGENDALI PID (PROPORTIONAL, INTEGRAL, DAN DERIVATIVE)
}

\author{
M. Nuzuluddin*, Danang Arengga, dan Anik Nur Handayani \\ Teknik Elektro, Fakultas Teknik, Universitas Negeri Malang \\ *Corresponding author, e-mail: m.nuzuluddin.1605518@ students.um.ac.id
}

\begin{abstract}
Abstrak - Energi sangat penting bagi kehidupan manusia, namun kini energi semakin menurun karena meningkatnya konsumsi energi yang tidak seimbang dengan supply. Untuk mengatasi masalah ini banyak energi alternatif telah dikembangkan, salah satunya adalah energi surya. Namun masalahnya adalah rendahnya tingkat efisiensi karena pentingnya posisi panel surya dengan matahari. Oleh karena itu diperlukan penjadwalan posisi panel surya sesuai dengan lintasan matahari. Untuk mendapatkan energi matahari yangs esuai dengan lintasnnya secara optimal ada dua hal yang harus diperhatikan sudut elevasi dan sudut azimuth. Kedua sudut ini akan menjadi titik kontrol panel surya, dan kedua sudut tersebut didapatkan dari pembacaan sensor yaitu sensor gyro untuk sudut elevasi dan kompas untuk sudut azimuth. Selanjutnya diolah kedalam mikrokontroller dengan menggunakan pengontrol PID (Proporsional, Integral, Derivatif) untuk mengontroll motor DC dalam penjadwalan posisi panel surya sesuai lintasan matahari. Dengan penggunaan kontrol PID dapat memperbaiki respon pada motor sehingga mengurangi error steady state dan dapat memberikan efek redaman pada sistem osilasi. Sehingga jadwal posisi panel surya sesuai lintasan matahari terkontrol dengan baik
\end{abstract}

\section{Kata Kunci : Panel Surya, PID, Sudut Elevasi, Sudut Azimut}

\begin{abstract}
Energy is very important for human life, but now the energy is getting decreased because of the increasing energy consumption that is not balance with the supply. In order to overcome these problem many alternative energy has been developed, one of which is solar energy. However the problem is low level of efficiency because the position of solar panels with the sun becomes very important. For optimum solar energy with optimal crossing there are two things to be aware of the elevation angle and azimuth angle. Both angles will be the control points of the solar panels, and these two angles are obtained from sensor readings of gyro sensors for elevation angles and compasses for azimuth angles. Further processed into microcontroller by using PID controller (Proportional, Integral, Derivative) to controll DC motor in solar panel position scheduling according to solar path. With the use of PID controls can improve the response on the motor thus reducing steady state errors and can provide damping effects on the oscillation system. So the schedule of solar panel position according to the path of the sun is well controlled
\end{abstract}

Keywords : Solar Tracking, PID, Solar Panel, Elevation Angle, Azimuth Angle

Copyright () 2017 JNTE. All rights reserved

\section{PENDAHULUAN}

Saat ini energi merupakan isu penting karena konsumsi energi terus meningkat seiring dengan laju pertumbuhan ekonomi dan populasi. Energi dapat dikategorikan menjadi 2, yaitu energi terbarukan dan energi yang tidak terbarukan, yang berarti energi tak terbarukan, bukan energi fosil, dan tidak dapat diperbaharui. Sebaliknya, energi terbarukan adalah energi yang berasal dari alam dan dapat diperbaharui seperti matahari, angin, air, biomassa, dan lain-lain. [1].

Matahari sebagai sumber energi memiliki gerakan yang harus diikuti oleh panel surya untuk mendapatkan energi secara optimal. Panel surya harus memiliki kemampuan untuk melacak lintasan pergerakan matahari. Sinar matahari datang setiap saat, yang disebabkan oleh pergerakan bumi yang berputar pada porosnya, atau biasa disebut rotasi bumi. Umumnya panel surya dipasang di instalasi tidak berubah posisi mengikuti sinar matahari. Hal ini menghasilkan tegangan output yang tidak optimal yang dihasilkan oleh panel surya [2].

Cara mengatasi hal ini adalah dengan menggunakan perangkat yang berfungsi menyesuaikan penjadwalan kemiringan panel surya. Penjadwalan ini juga berfungsi untuk 
mengatur perubahan sudut panel surya. Hal ini agar setiap saat berubah, panel surya bisa meningkatkan input paparan sinar matahari. Jika radiasi matahari yang diterima oleh panel surya dapat ditingkatkan, maka akan meningkatkan tegangan output panel surya bila dibandingkan dengan panel surya dengan tidak ada penjadwalannya. Oleh karena itu, dibutuhkan pengendali yang bisa mengendalikan pergerakan pada panel surya. Dalam tulisan ini perancang controller menggunakan PID untuk mengendalikan posisi panel surya sesuai lintasan matahari secara optimal berdasarkan pergerakan sudut elevasi dan sudut azimuth dengan menggunakan simulink pada MATLAB. MATLAB adalah bahasa tingkat tinggi dan lingkungan yang interaktif untuk perhitungan numerik, visualisasi, dan pemrograman. Dengan menggunakan MATLAB, kita dapat menganalisis data, mengembangkan algoritma, dan membuat model dan aplikasi $[3,4]$.

\section{TINJAUAN PUSTAKA}

\subsection{Motor DC}

Motor DC bekerja berdasarkan prinsip gaya elektromagnetik sehingga ketika motor diberikan daya, arus akan mengalir ke motor dan menghasilkan torsi putar yang sebanding dengan arus [5]. Pada sistem ini digunakan power window motor DC. Pemodelan Rangkaian internal Motor DC sederhana dan analisisnya ditunjukkan oleh Gambar 1:
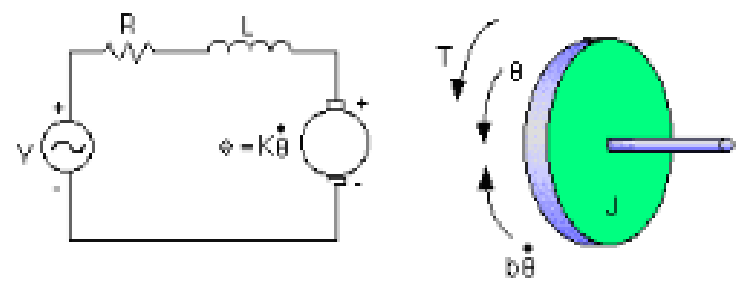

Gambar 1. Rangkaian motor [5].

\subsection{Kendali PID}

Pengendali PID ini paling banyak dipergunakan karena sederhana dan mudah dipelajari serta tuning parameternya. Lebih dari 95\% proses di industri menggunakan pengendali ini. Pengendali ini merupakan gabungan dari pengedali proportional $(\mathrm{P})$, integral (I), dan derivative (D) $[5,6]$. Blok diagram dari sistem pengendali dengan untai tertutup (closed loop) ditunjukkan oleh Gambar 2.

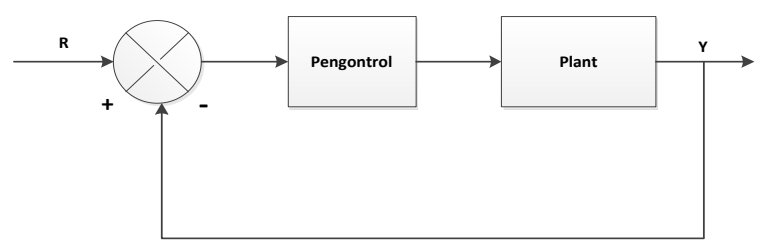

Gambar 2. Blok diagram sistem close loop [7].

Pada kebanyakan sistem pengaturan kecepatan, yang diinginkan adalah menjaga konstan kecepatan putar untuk segala kondisi beban, bukan mengatur agar kecepatan putarnya berubah-ubah setiap waktu mengikuti masukan acuan yang berubah. Tidak demikian halnya dengan sistem pengaturan posisi. Pada sistem ini, akurasi sistem biasanya diukur tidak hanya dengan steady-state error untuk masukan step, tetapi juga dengan steady-state error untuk masukan yang berubah dengan waktu. Hal ini biasanya diistilahkan sebagai foollowing error. Penambahan kontroler PD ternyata dapat memperbaiki kinerja sistem pengaturan posisi dalam hal besarnya following error ini.

\section{METODOLOGI}

Proses penelitian dan perancangan melalui beberapa tahap secara sistematis, agar diperoleh data yang akurat. Dimulai dengan pengumpulan data, perancangan, pembuatan alat, pengujian, hingga analisis hasil sistem. Perancangan perangkat panel surya diawali dengan penggunaan catu daya sebagai sumber tegangan rangkaian. Sudut elevasi dan sudut azimut untuk menentukan titik setel. Sensor gyro dan kompas digunakan sebagai sensor posisi. Mikrokontroler ATmega 328 (Arduino Nano) digunakan sebagai unit dalam pelacakan matahari untuk penjadwalan panel surya. Sedangkan pada output motor DC terdiri dari yang digunakan untuk menggerakkan panel surya. Hal ini ditunjukkan dalam blok diagram alat pada Gambar 3.

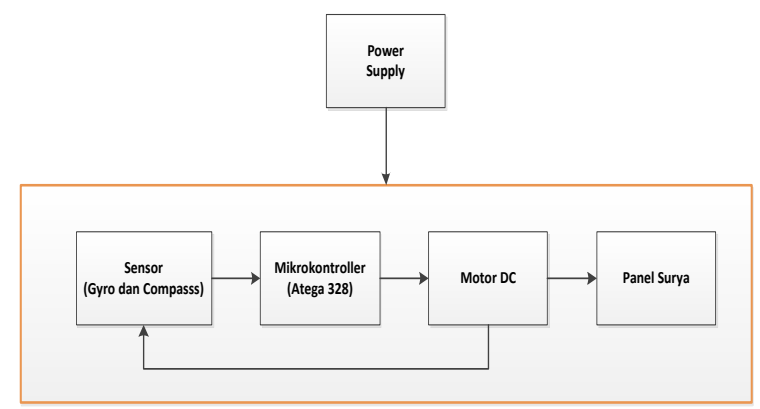

Gambar 3. Blok diagram sistem. 


\subsection{Perubahan Posisi Panel Surya}

Gambar 4 menunjukkan pelacakan posisi matahari sesuai sudut elevasi, perubahan posisi kemiringan panel surya, dengan asumsi posisi matahari terbit pukul 09.00 WIB dan terbenam jam 17.00 WIB. Posisi matahari berpengaruh pada kemiringan panel surya. Pada posisi pertama, panel surya memiliki sudut $-45^{\circ}$ untuk menangkap sinar matahari dari pukul 09.00 WIB - 10.00 WIB. Panel surya akan berubah ke posisi 2 saat jam menunjukkan pukul $10.00 \mathrm{WIB}$ pada sudut $-30^{\circ}$ untuk menangkap sinar matahari pada pukul 10.00 WIB - 11.00 WIB. Selanjutnya pada posisi 3, 4, 5, 6, ke 7. Setelah pukul $15.00 \mathrm{WIB}$, posisi panel akan kembali ke posisi 1 untuk menangkap sinar matahari keesokan harinya.

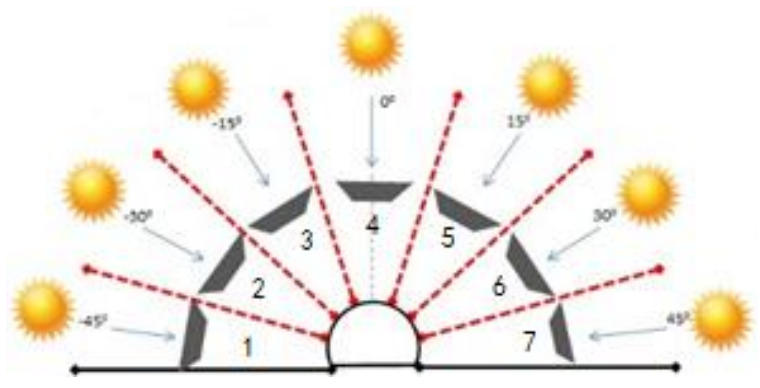

Gambar 4. Posisi panel surya terhadap matahari berdasarkan sudut elevasi

Sedangkan berdasarkan sudut azimut pada sistem ini selain bergerak dengan berdasarkan sudut elevasi juga bergerak berdasarkan pergerakan harian matahari sehingga membentuk sudut, dan sudut itu adalah sudut azimuth. Matahari akan nampak bergerak dari khatulistiwa (khatulistiwa) antara 23,5 derajat lintang utara dan lintang selatan.

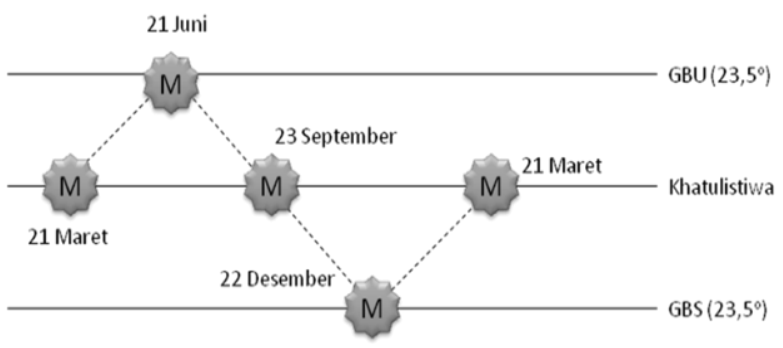

Gambar 5. Posisi sudut panel surya terhadap matahari berdasarkan sudut azimuth [8].

Pada 21 Maret - 21 Juni, matahari bergeser dari garis khatulistiwa ke arah utara dan akan membalik arah setelah mencapai 23,5 derajat lintang utara dan bergerak kembali ke arah garis katulistiwa. Setelah itu, matahari akan nampak bergerak ke selatan dan membalikkan arah setelah mencapai 23,5 derajat lintang selatan. Hal ini ditunjukkan oleh Gambar 5.

\subsection{Diagram Alir Sistem}

Proses kerja sistem ini adalah mikrokontroler, sensor, dan motor DC dengan sumber tenaga. Saat mikrokontroler dinyalakan maka panel secara otomatis akan mengubah posisi sesuai dengan penjadwalan yang telah dibuat. Jika jadwal waktu berikutnya berjalan maka panel surya akan berubah posisinya ke posisi selanjutnya, hal ini ditunjukkan oleh Gambar 6.

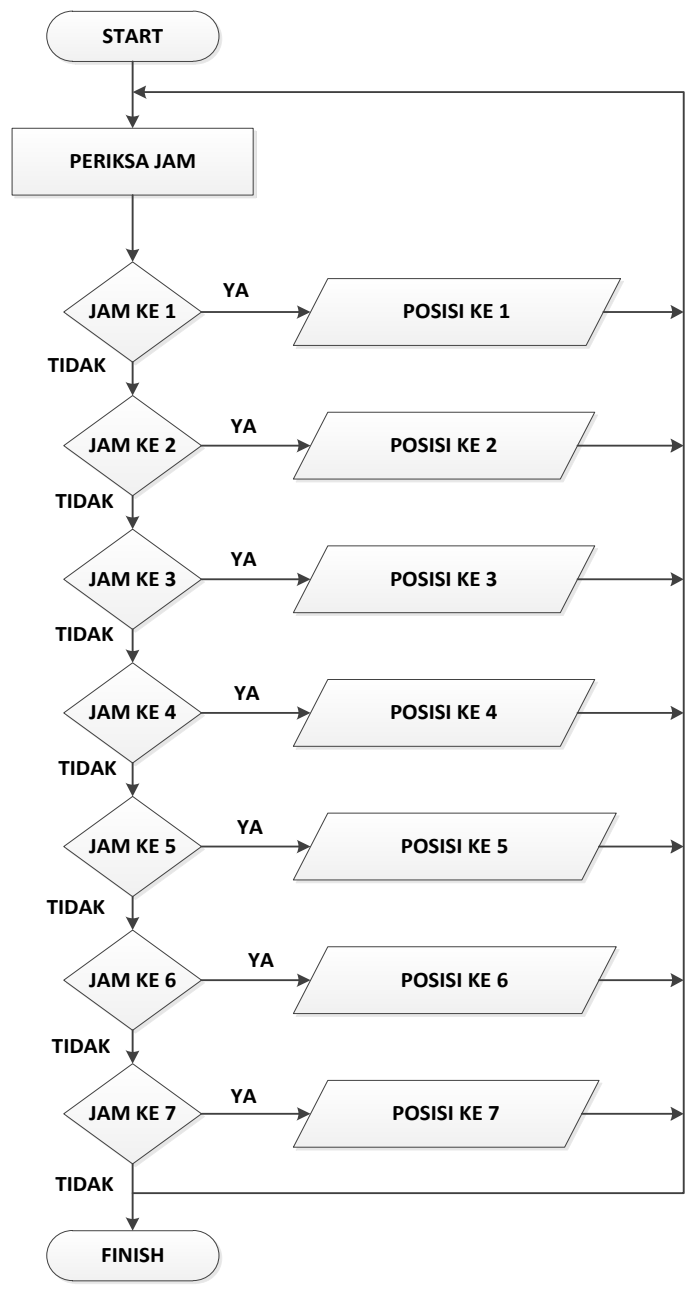

Gambar 6. Diagram alir system

\subsection{Pengontrolan Sistem}

Pada sistem pengaturan kecepatan, masalahnya adalah menentukan berapa banyak 
energi listrik yang harus diaplikasikan untuk memutar motor pada kecepatan yang diinginkan, terlepas dari kondisi beban bergerak. Pada sistem penentuan posisi, masalahnya terutama pada berapa lama energi listrik harus diaplikasikan pada drived beban motor yang menempel pada posisi yang diinginkan, tidak lebih dan tidak kurang. Konfigurasi sederhana untuk mencapai tujuan tersebut adalah sistem pengaturan posisi loop tertutup yang di tunjukkan pada Gambar 7.

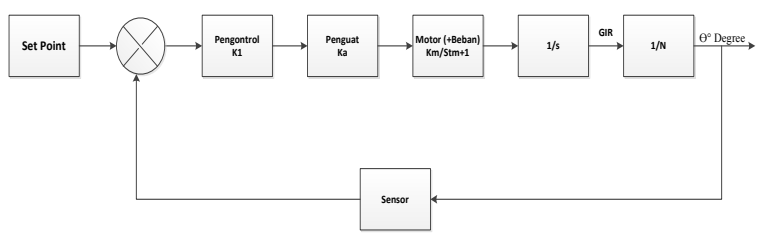

Gambar 7. Sistem kontrol posisi motor DC

Pemikiran yang mendasari konfigurasi ini adalah memberikan sinyal error (tentu saja itu sudah diperkuat) sebagai input energi untuk motor. Selama terjadi error, yang berarti bahwa posisi beban tidak sesuai dengan yang diinginkan, motor akan bergerak karena mendapat masukan energi. Jika posisi yang diinginkan tercapai, motor tidak lagi mendapat input energi sehingga bebannya akan tetap berada pada posisi itu $[9,10]$.

Untuk harga penguat sistem yang besar, sistem di atas memiliki stabilitas relatif rendah: respons terhadap input langkah memiliki overshoot maksimum dan osilasi yang besar. Hal ini dapat dibuktikan secara matematis. Penjelasan fisik diperoleh dengan menghubungkan prinsip kerja di atas dengan konsep inersia atau dengan mempertimbangkan keterlambatan respons sistem (yang dimodelkan oleh kutub atau konstanta waktu). Motor listrik tidak akan langsung berputar pada kecepatan pengenal sehingga diberi tegangan nominal. Begitu pula motor tidak akan segera berhenti berputar begitu catu daya terputus.

Salah satu cara untuk meningkatkan kinerja sistem penentuan posisi di atas adalah dengan memberikan umpan balik kecepatan. Pada sistem ini, input motor bukan sinyal error namun sinyal error berkurang kecepatannya. Sistem ini terbukti memiliki stabilitas relatif lebih baik. Dalam sistem ini, keakuratan sistem biasanya diukur tidak hanya dengan error steady-state untuk proses input, tetapi juga dengan error steady-state untuk variasi waktu. Hal ini biasanya disebut sebagai error yang fatal. Penambahan kontroler PD dapat memperbaiki kinerja sistem penentuan posisi dalam hal besarnya setelah error ini.

\subsubsection{Motor DC}

Persamaan torsi yang dibangkitkan oleh Motor DC dapat didekati secara linear menurut persamaan berikut ini :

$T=K_{a} i$

Dimana $K a$ dalah konstanta jangkar motor yang bergantung pada banyaknya lilitan pada jangkar, jumlah kutub medan, tipe belitan dan penampang jangkarnya. Adapun besarnya tegangan ggl induksi lawan yang dibangkitkan motor ketika berputar adalah sebanding dengan konstanta motor $K b$ dan kecepatan sudut putaran motor $(\theta)$ :

$e=K_{b} \dot{\theta}$

Dengan menggunakan hukum newton, bahwa persamaan torsi yang terkait dengan momen inersia dan rasio redaman dari motor adalah:

$T=J \ddot{\theta}+b \dot{\theta}$

dari persamaan (1) dan (3) diperoleh:

$i=\frac{J \ddot{\theta}+b \dot{\theta}}{K_{a}}$

Sedangkan besarnya tegangan $\mathrm{V}$ menurut hukum kirchoff adalah :

$$
\begin{aligned}
& V=i R+L \frac{d i}{d t}+e \\
& V=i R+L \frac{d i}{d t}+K_{b} \dot{\theta}
\end{aligned}
$$

Dengan melaplacekan persamaan (4) dan (6) dan mensubstitusikannya, maka diperoleh fungsi transfer antara posisi sudut motor è terhadap tegangan armature $\mathrm{V}$ dimana $K a=K b$

$$
\frac{\theta(s)}{V(s)}=\frac{K}{s\left((J s+b)(L s+R)+K^{2}\right)}
$$

Persamaan (7) diatas memiliki 5 konstanta yang belum diketahui. Nilai-nilai ini pada dasarnya bisa berasal dari percobaan identifikasi 
plant. Dalam tulisan ini telah dilakukan proses identifikasi plant pada konstanta motor DC. Konstanta digambarkan sebagai berikut:

1. Momen inersia rotor $(\mathrm{J})=0.1 \mathrm{~kg} \cdot \mathrm{m}^{2} / \mathrm{s}^{2}$

2. Rasio redaman sistem mekanik motor $(b)=$ $0.01 \mathrm{Ns} / \mathrm{m}$

3. Konstanta Motor $(K=K b=K a)=0.3 \mathrm{Nm} / \mathrm{A}$

4. Resistansi $(R)=2 \Omega$

5. Induktansi $(L)=0.4 \mathrm{H}$

sehingga diperoleh fungsi transfer sebagai berikut:

$\frac{\theta(s)}{V(s)}=\frac{30}{4 s^{3}+20 s^{2}+13 s}$

Kontroler PID adalah jenis pengendali yang banyak diterapkan dalam pengendalian proses industri karena kesederhanaan strukturalnya, lebih tahan terhadap gangguan luar dan dapat diterapkan dalam berbagai kondisi operasi. Tapi pengendali PID perlu disetel dengan benar untuk menentukan harga kontrol konstanta proporsional, integral dan derivative yang mengoptimalkan kinerja sistem. Setelah tiga parameter disetel, nilai parameter kontrol pada PID biasanya dipertahankan sepanjang proses kontrol $[10,11,14]$.

Dasar sebuah sistem kontrol close loop, yang ditunjukkan pada Gambar 8, terdiri dari sebuah kontroler dan sebuah pabrik. Dalam tulisan ini PID digunakan sebagai pengontrol. Kontroler PID terdiri dari tiga komponen: proporsional, integral dan turunan. Kontroler PID menggunakan persamaan kontrol berikut:

$$
C(s)=K_{p}\left(1+\frac{1}{T_{i} s}+T_{d} s\right)=\frac{K_{d} s^{2}+K_{p} s+K_{i}}{s}
$$

Dimana $K_{p}$ adalah parameter proporsional, $K_{i}=\frac{K_{p}}{T_{i}}$ adalah parameter integral dan $K_{d}=$ $K_{p} x T_{d}$ adalah parameter derivatif. Dalam perancangan pengendali PID, ketiga konstanta tersebut harus dipilih agar sistem close-loop memberikan respon yang diinginkan.

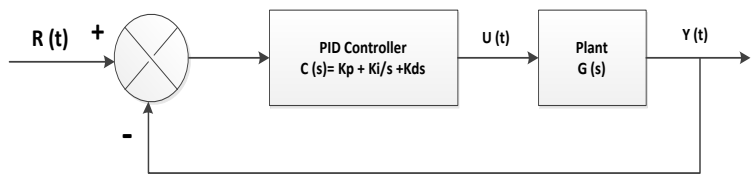

Gambar 8. Blok digram sistem close loop [10]
Respon yang diinginkan haruslah memiliki settling time yang minimal dengan overshoot yang kecil atau tanpa overshoot dari respon step sistem close-loop $[8,10,11]$. Sistem close loop tersebut ditunjukkan oleh Gambar 8.

\section{HASIL DAN PEMBAHASAN}

Mengontrol sistem pelacakan panel surya dengan menggunakan kontroler PID dapat disimulasikan dengan menggunakan SIMULINK pada MATLAB [1,3].

\subsection{Kontrol Proporsional (P)}

Gambar 9 menunjukkan bentuk blok diagram sederhana dari kontrol proporsional. Unit mototr DC merupakan transfer function dari persamaan 8 menunjukkan bentuk persamaan yang diproleh dari konstantakonstanta motor DC yang dipakai, sedangkan nilai Kp diperoleh dari trial and error sistem sehingga diperoleh respon output yang baik.

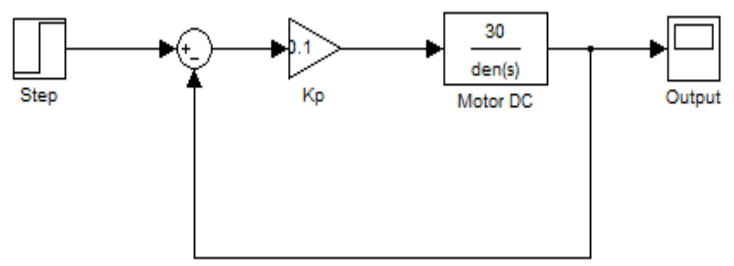

Gambar 9. Blok diagram kontrol proportional

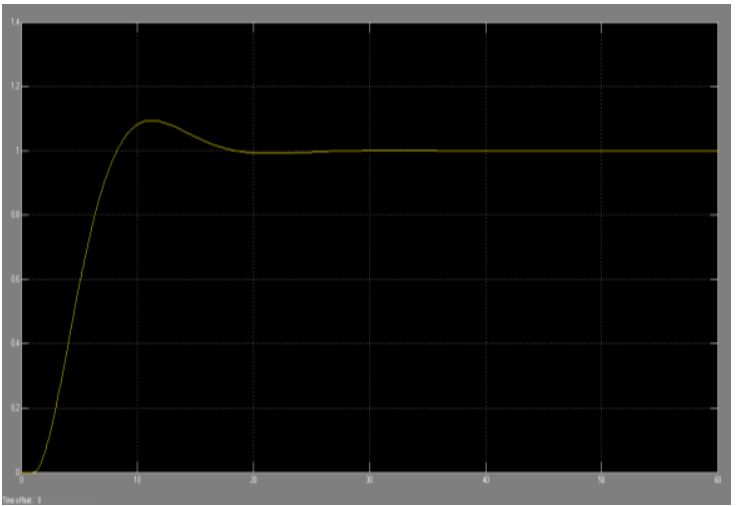

Gambar 10. Output kontrol proporsional

Gambar 10 di atas respon keluaran osilasi kontinu tidak dapat steady state pada set point. Karena sistem di atas dalam close loop tanpa pengontrol apapun. Kontrol proporsional memberikan efek langsung (sebanding) dengan tingkat kesalahannya. Semakin besar kesalahannya, semakin besar sinyal kontrol yang 
dihasilkan pengontrol. Sehingga dapat memperbaiki respon transien terutama: rise time, settling time.

\subsection{Kontrol Proprtional-Integral (PI)}

Kontrol PI adalah jumlahan error setiap waktu dan melakukan akumulasi offset yang sebelumnya telah di perbaiki. Error terakumulasi dan dikalikan dengan konstanta ingtegral (Ki) dan menjadi keluaran kontroler. Hal ini ditunjukkan oleh Gambar 11.

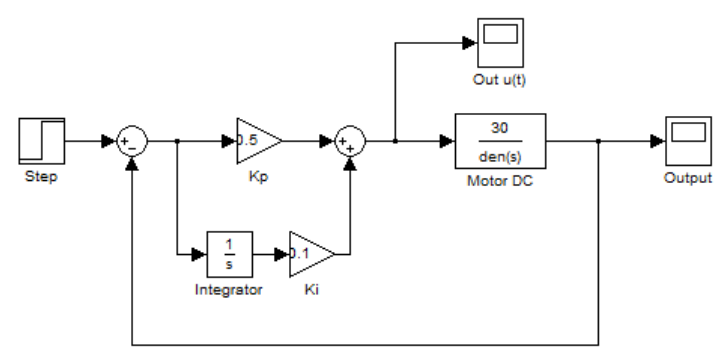

Gambar 11. Blog diagram kontrol PI

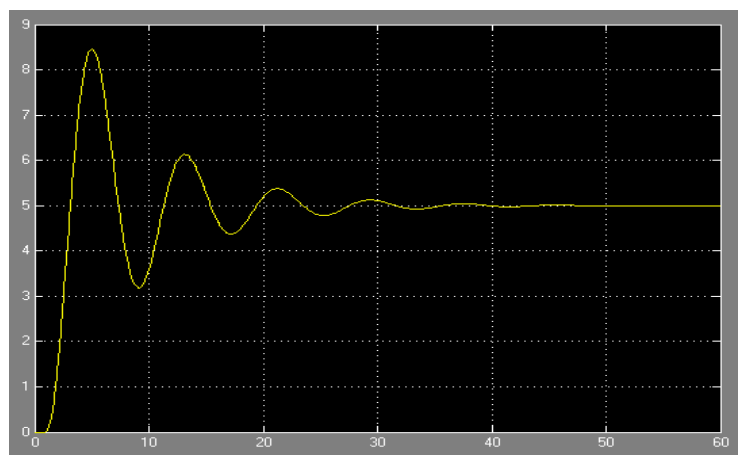

Gambar 12. Output kontrol PI

Dari hasil keluaran yang ditunjukkan oleh Gambar 12 dapat disimpulkan bahwa pengaruh kontrol integral pada sistem mampu menghilangkan error steady state, respon lebih lambat (dari P), dan dapat menyebabkan ketidakstabilan pada sistem.

\subsection{Kontrol Proportional-Derivative (PD)}

Kontrol derivatif hanya berubah saat ada perubahan error. Hal ini juga menyebabkan kontrol derivatif tidak dapat berdiri sendiri. Maka keluaran yang dihasilkan tergantung pada nilai $\mathrm{Kd}$ dan laju perubahan sinyal error. Untuk mensimulasikan hal tersebut maka perlu memasukkan blog diagram pada Gambar 13.

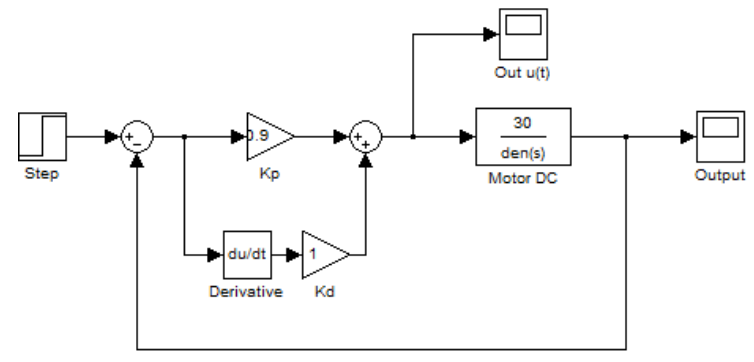

Gambar 13. Blok diagram kontrol PD

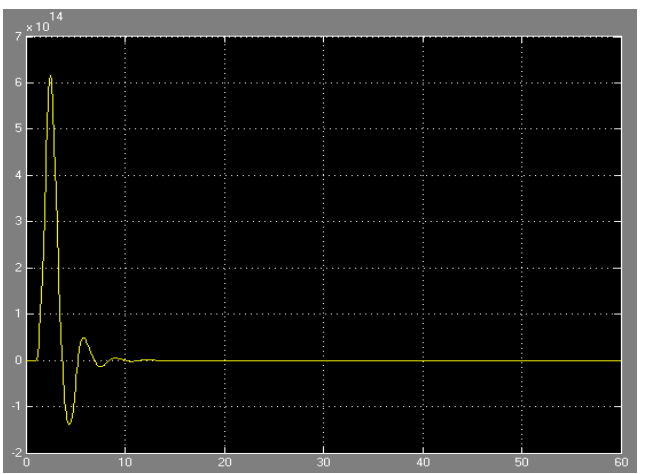

Gambar 14. Output Kontrol PD

Gambar 14 menunjukkan Output kontrol PD memberi efek pada sistem yaitu (1) memberikan efek redaman pada sistem osilasi sehingga dapat memperbesar nilai Kp; (2) Tingkatkan respon transien, karena memberikan tindakan bila terjadi error; (3) D hanya berubah bila terjadi kesalahan perubahan, maka bila ada kesalahan statis D tidak beraksi maka D tidak bisa digunakan sendiri.

\subsection{Proportionsal - Integral - Derivative (PID) Controller}

Gambar 15 menunjukkan blok diagram penggabungan kontrol $\mathrm{P}$, I dan D dengan nilai konstanta masing-masing setelah dilakukan trial \& error sehinga kondisi kontrol menjadi lebih baik.

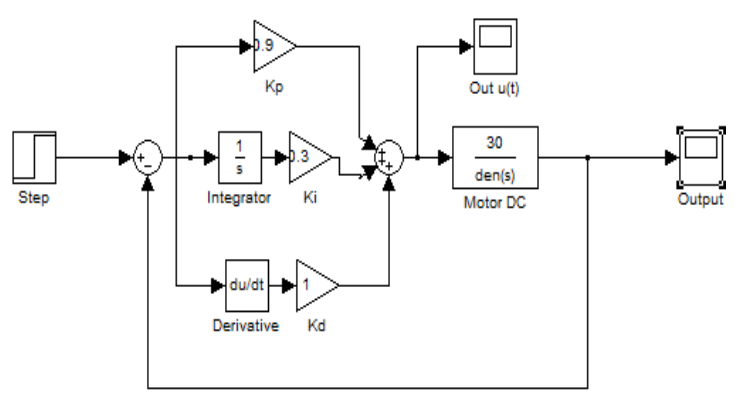

Gambar 15. Blok diagram kontrol PID 


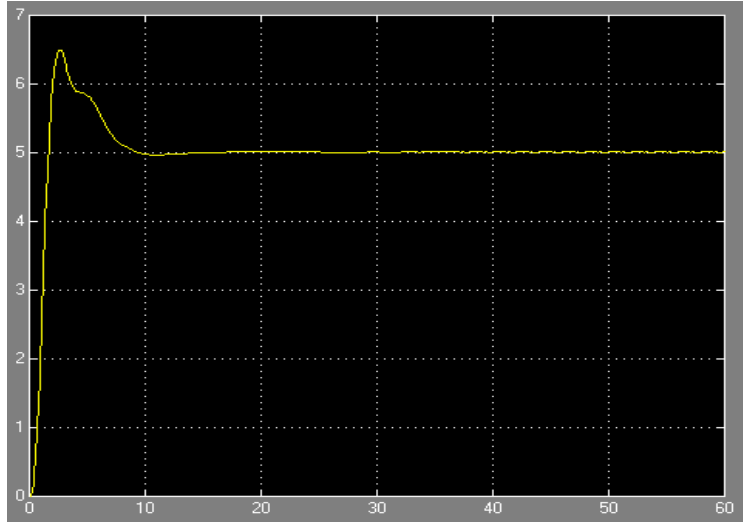

Gambar 16. Output Kontrol PID

Kontrol PID sebenarnya terdiri dari 3 jenis susunan yang saling digabungkan, yaitu $P$ (Proporsional) Controller, D (Derivative) Controller, dan I (Integral) Controller. Masingmasing memiliki parameter tertentu yang harus diatur agar beroperasi dengan benar, disebut konstanta. Setiap jenis, memiliki kelebihan dan kekurangan tersendiri. Hal ini dapat dilihat dari Gambar 16 di atas dan dijelaskan melalui tabel di bawah ini :

Tabel 1. Respon Kontrol PID

\begin{tabular}{|l|l|l|l|l|}
\hline $\begin{array}{c}\text { Respon } \\
\text { Close } \\
\text { Loop }\end{array}$ & Rise Time & Overshoot & $\begin{array}{l}\text { Settling } \\
\text { Time }\end{array}$ & $\begin{array}{l}\text { Error } \\
\text { Steady } \\
\text { State }\end{array}$ \\
\hline Proporsional & $\begin{array}{l}\text { Menurun- } \\
\text { kan }\end{array}$ & $\begin{array}{l}\text { Meningkat- } \\
\text { kan }\end{array}$ & $\begin{array}{l}\text { Perubahan } \\
\text { Kecil }\end{array}$ & $\begin{array}{l}\text { Menurunkan/ } \\
\text { Mengurangi }\end{array}$ \\
\hline Integral & $\begin{array}{l}\text { Menurun- } \\
\text { kan }\end{array}$ & $\begin{array}{l}\text { Meningkat- } \\
\text { kan }\end{array}$ & $\begin{array}{l}\text { Meningkat- } \\
\text { kan }\end{array}$ & $\begin{array}{l}\text { Mengelimi- } \\
\text { nasi }\end{array}$ \\
\hline Derivatif & $\begin{array}{l}\text { Perubahan } \\
\text { Kecil }\end{array}$ & $\begin{array}{l}\text { Menurunka } \\
\mathrm{n}\end{array}$ & $\begin{array}{l}\text { Menurun- } \\
\text { kan }\end{array}$ & $\begin{array}{l}\text { Perubahan } \\
\text { Kecil }\end{array}$ \\
\hline
\end{tabular}

Paper ini menggambarkan data bahwa jika panel surya mendapatkan penjadwalan panel surya dengan di kontrol dengan sistem PID. Hal ini didasarkan pada pengukuran data kontrol dengan menggunakan kontroler PID seperti pada tabel di bawah ini:

Tabel 2. Data Pengukuran

\begin{tabular}{cccc}
\hline JAM & \multicolumn{2}{c}{ SUDUT } & \multirow{2}{*}{ Error } \\
\cline { 2 - 3 }$($ WIB $)$ & Sebenarnya & Pengukuran & \\
\hline 09.00 & -45 & -47 & -2 \\
\hline 10.00 & -30 & -36 & -6 \\
\hline 11.00 & -15 & -11 & 4 \\
\hline 12.00 & 0 & -1 & -1 \\
\hline 13.00 & 15 & 10 & -5 \\
\hline 14.00 & 30 & 27 & 3 \\
\hline 15.00 & 45 & 41 & -4 \\
\hline
\end{tabular}

Pada Tabel 2 diperoleh hasil pengukuran derajat pengukuran, terjadinya error yang disebabkan oleh ruang pada roda gigi motor DC. Hal ini bisa diatasi dengan perlengkapan perbaikan pada motor. Gear motor DC bisa dilihat pada Gambar 17.
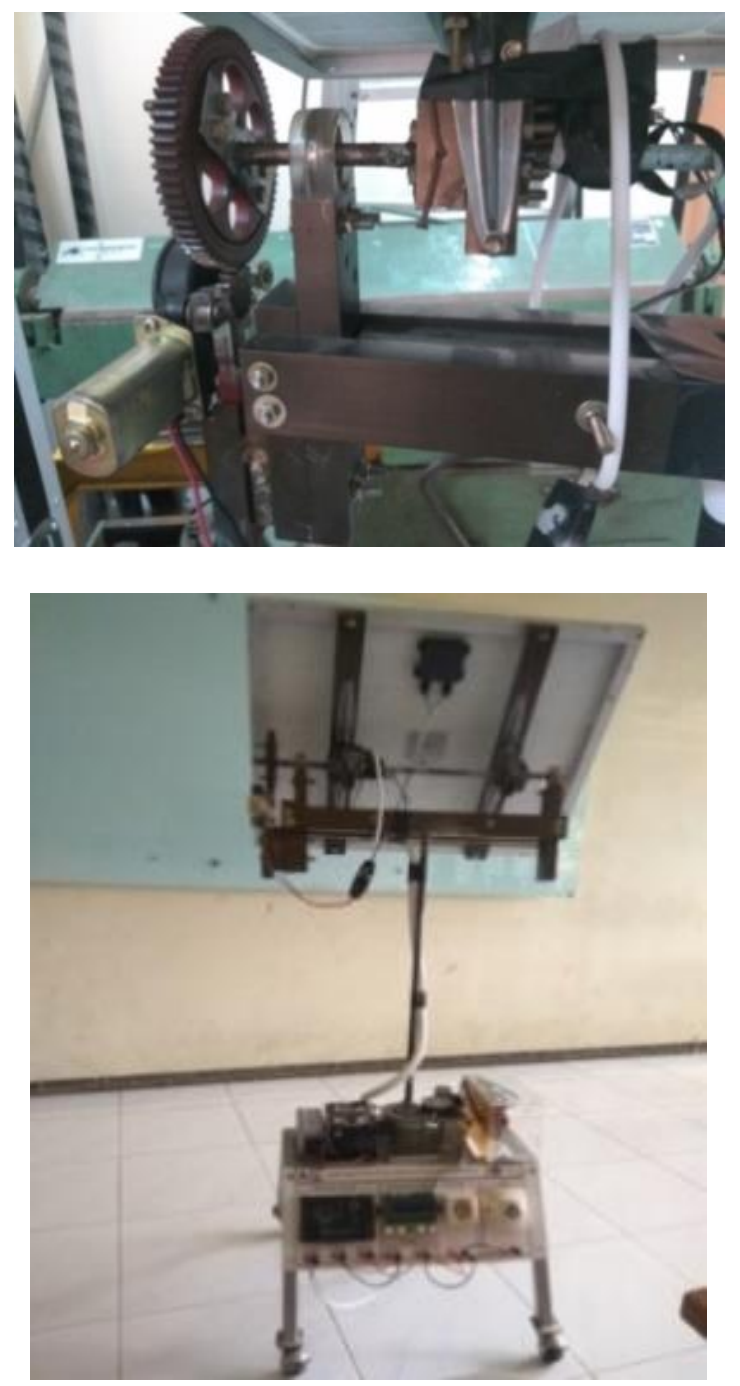

Gambar 17. Gir Motor DC pada Prototype Penjadwalan Posisi Panel Surya

\section{KESIMPULAN}

Dari percobaan yang dilakukan melalui trial and error antara kontrol proporsional, integral, dan derivatif dapat diidentifikasi efek yang diberikan oleh masing-masing yaitu kontrol Proporsional berperan dalam mempercepat waktu baca penjadwalan panel surya sesuai set point yang dinginkan. Kontrol Integral digunakan untuk 
menghilangkan error sehingga sistem menjadi stabil. Sedangkan kontrol derivatif berperan dalam mengurangi overshoot.

Umumnya dalam merancang sistem kontrol PID dilakukan dengan sistem cobacoba (trial \& error). Hal ini disebabkan parameter Kp, Ki dan Kd tidak independent. Oleh karena itu untuk mendapatkan respon kontrol yang baik diperlukan langkah trial \& error dengan kombinasi antara P, I dan D sampai ditemukan nilai $\mathrm{Kp}$, Ki dan Kd untuk respon output yang baik.

Dengan menggabungkan kontrol Proporsional, Integral dan Derivatif untuk penjadwalan posisi panel surya mulai jam $09.00 \mathrm{~s} / \mathrm{d} 15.00$ dapat terkontrol dengan baik walaupun ada sedikit error sekitaran sudut $1^{\circ}$ $-6^{\circ}$ dari posisi matahari. Selain itu, kontrol PID dapat memperbaiki respon motor dengan mengurangi error steady state dan memberikan efek redaman sistem osilasi sehingga alat bisa berjalan dengan baik. Dengan nilai kontrol yang diberikan yaitu $\mathrm{Kp}=0.9, \mathrm{Ki}=0.3$, dan $\mathrm{Kd}=1$ sehingga didapati output stabil dan baik.

\section{DAFTAR PUSTAKA}

[1] Wardhany, Arum Kusuma. 2013. Pengaruh Ekstrak Hibicus Rosa-Sinensis Terhadap Daya Serap Sel Fotovoltaik. Surakarta: Tugas Akhir, Universitas Muhammadiyah Surakarta.

[2] Eduardo, Lorenzo. Solar Electricity. http://book.google.co.id/books?id=1Yc53 xZyxZQC\&printsec $=$ frontcover\& $\mathrm{dq}=$ Solar+Electricity.html (Accessed on 6 May 2017)

[3] Ogata. 1992. MatLab High Performance Numeric Computation and Visualization Software. The Mathworks, Inc. Engineering Problems with MatLab. Englewood Cliffs, New Jersey : Prentice Hall Inc.

[5] Joelianto, E. \& Tansri, O. Fuzzy Logic Based Hybrid Reference Control for Improving Transient Response Performance of PID Controller. ITB
Journal，39A， 124-145，2007. (In Indonesian)

[6] Y. Peng, J. Luo, J. Zhuang, C. Wu. "Model reference fuzzy adaptive PID control and its applications in typical industrial processes", "IEEE/ICAL", pp.896-901, Sep. 2008.

[7] Soloman, Sabrie. 2010. Sensors and Control Systems in Manufacturing. United States: McGraw-Hill Companies.

[8] Åström, K.J. \& Hägglund, T. PID Controllers: Theory, Design, and Tuning, 2nd Ed. Instrument Society of America, USA, 1995.

[9] Wescott Tim. 2000. PID Without PhD. India : EE Times

[10] Misir, D. \& Malki, H.A., Liapunov. Stability for A Fuzzy PID Controlled Flexible-Joint Manipulator. International Journal of Computer Applications in Technology, 27, 97-106, 2006.

[11] Ziegler, J. G.\& N.B. Nichols. 1942. Optimum Setting for Automatic Controllers. Tans: ASME

[12] Messner, William and Dawn Tilbury. 1999. Control Tutorials for MatLab and Simulink. A Web Based Approach. Addisson Wesley, Inc.

[13] Ogata, Katsuhiko. 1997. Modern Control Engineering. 3rd ed. Prentice Hall International.

[14] PEMBERTON, T. J., 1972. PID: The logical control algorithm, parts I \& II. Control Engineering, 19, May, (66-67), July, (61-63)

\section{Biodata Penulis}

M. Nuzuluddin, Mahasiswa Prodi Pendidikan Kejuruan, Pascasarjana , Universitas Negeri Malang.

Danang Arengga, Mahasiswa Prodi Pendidikan Teknik Elektro, Fakultas Teknik, Universitas Negeri Malang

Anik Nur Handayani, Dosen Program Magister Pendidikan Kejuruan Pascasarjana Universitas Negeri Malang dan Pendidikan Teknik Elektro, Fakultas Teknik, Universitas Negeri Malang 